\title{
Case-control study of risk factors for infectious mastitis in Spanish breastfeeding women
}

\author{
Pilar Mediano, Leónides Fernández, Juan M Rodríguez and María Marín*
}

\begin{abstract}
Background: The purpose of this study was to identify potential predisposing factors associated with human infectious mastitis.

Methods: We conducted a case-control study among breastfeeding women, with 368 cases (women with mastitis) and 148 controls. Data were collected by a questionnaire designed to obtain retrospective information about several factors related to medical history of mother and infant, different aspects of pregnancy, delivery and postpartum, and breastfeeding practices that could be involved in mastitis. Bivariate analyses and multivariate logistic regression model were used to examine the relationship between mastitis and these factors.

Results: The variables significantly- and independently-associated with mastitis were cracked nipples $(P<0.0001)$, oral antibiotics during breastfeeding $(P<0.0001)$, breast pumps $(P<0.0001)$, topical antifungal medication during breastfeeding $(P=0.0009)$, mastitis in previous lactations $(P=0.0014)$, breast milk coming in later than $24 \mathrm{~h}$ postpartum $(P=0.0016)$, history of mastitis in the family $(P=0.0028)$, mother-infant separation longer than $24 \mathrm{~h}$ $(P=0.0027)$, cream on nipples $(P=0.0228)$ and throat infection $(P=0.0224)$.

Conclusions: Valuable factors related to an increased risk of infectious mastitis have been identified. This knowledge will allow practitioners to provide appropriate management advice about modifiable risk factors, such as the use of pumps or inappropriate medication. They also could identify before delivery those women at an increased risk of developing mastitis, such as those having a familial history of mastitis, and thus develop strategies to prevent this condition.
\end{abstract}

Keywords: Breastfeeding, Infectious mastitis, Risk factors, Public health, Epidemiology

\section{Background}

Infectious mastitis is a common condition that affects up to $33 \%$ of women during lactation, although its incidence may be underestimated because of differences in case definition and reporting [1-4]. However, as it has recently been addressed [5], most of the studies have not reported the true mastitis incidence to date, since it would be necessary to define a time limit for the collection of data and to know the size of the population at risk, that is, breastfeeding mothers in the area of study. On one hand, the term "infectious mastitis" has been applied only to acute cases, with both local (breast redness, engorgement and pain) and systemic symptoms; however, subacute mastitis, that include only local symptoms

\footnotetext{
* Correspondence: mlmarin@vet.ucm.es

Departamento de Nutrición, Bromatología y Tecnología de los Alimentos, Universidad Complutense de Madrid, 28040 Madrid, Spain
}

and are often characterized by a reduced milk secretion, have been systematically underreported. On the other hand, human milk cultures are rarely performed and, therefore, there are not standardized sampling and analysis procedures [6].

Lactational mastitis constitutes one of the main medical causes of premature weaning due to pain and discomfort or as a result of inappropriate advise of a health professional $[7,8]$. Since breastfeeding provides a wide range of health benefits for the mother-infant pair [9-11], mastitis constitutes a relevant Public Health issue $[6,12]$. Some epidemiologic studies have been carried out to investigate the incidence and the potential risk factors that could be involved in infectious lactational mastitis $[1,3,7,13-15]$. Risk factors that have been suggested to be strongly associated to mastitis include, among others, mastitis with a previous child, cracked or sore nipples,

\section{Biomed Central}


use of ointments, inappropriate breastfeeding practices, and peripartum antibiotherapy [1,4,13-15].

In Spain, the most recent National Survey of Health available (2011-2012) showed that the estimated prevalence of exclusive (mixed) breastfeeding was 66.2 (72.4)\%, $53.6(66.6) \%$ and $28.5(46.9) \%$ at 6 weeks, 3 months and 6 months, respectively, after birth [16]. On the other hand, Spain ranks regular (24 out of 36) in the Breastfeeding Policy Scorecard for Developed Countries published recently [17] according to maternity leave laws and right to daily nursing breaks, among other indicators. Furthermore, the number of centers that hold the Baby Friendly Hospital designation as institutions that promote breastfeeding, as well as the Breastfeeding Support Groups, has increased during the last decade. However, in contrast to this renewed interest that breastfeeding and human milk are receiving nowadays, lactational mastitis still remains widely unknown to the medical community, including the Spanish practitioners. In this sense, the Recommendations on Breastfeeding of the Lactation Committee of the Spanish Association of Paediatrics [18] do not even mention mastitis as a common condition during lactation and one of the main medical causes of premature weaning.

In this study, a broad range of risk factors have been evaluated in a Spanish population. We have addressed some risks factors from literature and others that have not been taken in account in previous studies. To our knowledge this is the first large epidemiological study about risk factors for infectious mastitis among lactating women in a Spanish population.

\section{Methods}

\section{Subject selection}

Cases $(n=368)$ who participated in this retrospective case-control study by filling out a questionnaire about mastitis risk factors, were recruited from 1080 lactating women with clinical symptoms of infectious mastitis who attended our laboratory from September 2009 to June 2011 to have a breast milk sample analyzed in the context of a study about microbiology of human mastitis.

They were referred to our laboratory by lactation consultants and midwives attending different health-care centers in Spain and all cases included either both local (breast redness, pain and engorgement) and systemic symptoms (fever or flu-like symptoms) or only local symptoms (pain, engorgement, reduced milk secretion). Patients suffering from Raynaud's syndrome, mammary abscesses or any other mammary pathology were excluded from the study. The diagnosis of mastitis was confirmed by milk cultures that were plated onto ready-touse Baird Parker (selective medium for staphylococci isolation) and Columbia Blood Agar for isolation of streptococci, staphylococci, corynebacteria and related bacteria. Violet Red Bile Glucose Agar was used for isolation of enterobacteria and other Gram-negative bacteria in order to confirm that the milk samples had not been contaminated. The plates were incubated at $37^{\circ} \mathrm{C}$ for $48 \mathrm{~h}$ and to reach a positive diagnosis of mastitis the following microbiological criteria was established: Staphylococcus aureus > $150 \mathrm{CFU} / \mathrm{mL}$, coagulase-negative staphylococci (mainly Staphylococcus epidermidis) $>1000 \mathrm{CFU} / \mathrm{mL}$ and viridans streptococci (mainly Streptococcus mitis and Streptococcus salivarius) > $1000 \mathrm{CFU} / \mathrm{mL}$ [19].

Midwives and lactation consultants were also asked to recruit healthy breastfeeding women with no clinical symptoms of mastitis during current lactation as the control group. In order to verify the absence of mastitis in the controls, breast milk samples were also cultured in the same media as mastitis samples. The mammary microbiota in controls was characterized by the presence of a relatively heterogeneous population at a moderated concentration $(<1000 \mathrm{CFU} / \mathrm{mL})$ and $<10^{3}$ white blood cells per $\mathrm{mL}$ of milk. Informed consent to the protocol approved by the Ethical Committee of Hospital Clínico San Carlos (Madrid, Spain) was obtained from the women involved in this study.

Cases and controls (all of them with full-term pregnancy and healthy children) were asked to fill out a questionnaire with precoded and open-ended questions designed to collect retrospective information on demographic characteristics, medical history of mother and infant, different aspects of pregnancy, delivery and postpartum, and breastfeeding practices (Tables 1, 2, 3 and 4). The questionnaire was completed and returned by 368 out of 1080 cases (34\%) and 148 out of 256 controls (58\%).

\section{Statistical analysis}

Continuous variables were expressed as means and 95\% confidence intervals (95\% CI) and percentages were calculated for categorical variables. Comparison of continuous and categorical variables in both control and mastitis groups was done using Student's t-test and chisquared test, respectively, and any statistically significant difference was noted. Fisher's exact test was used as appropriate. Odds Ratio (OR) associated with each potential factor involved in mastitis (risk or protective factor) and $95 \%$ CI were calculated to compare exposures in each group. For the purpose of the study, $P<0.05$ was considered statistically significant.

The relationship between mastitis risk and seventyeight variables was first examined by bivariate analysis. To analyze the strength of association between mastitis and the potential risk factors, most factors that were statistically significant in the bivariate analysis, based on a $P<0.05$ significance level (thirty-four variables), were used in a multivariate logistic regression model using the maximum likelihood method of the LOGISTIC procedure of SAS. Variables were included one at a time in the multivariate model using the forward stepwise 
Table 1 Medical history of women participating in the study

Variables

$\begin{array}{lc}\text { A } & 158(44.13) \\ B & 28(7.82) \\ A B & 19(5.31) \\ O & 153(42.74)\end{array}$

Rh factor

Positive

$275(78.13)$

$77(21.88)$

Mastitis in the family

$\begin{array}{ll}\text { No } & 191(62.01) \\ \text { Yes } & 117(37.99)\end{array}$

Mastitis in previous breastfeedings**

$$
\text { No }
$$

Yes

53 (48.62)

$56(51.38)$

Breast cancer in the family

$$
\text { No }
$$

Yes

265 (74.44)

$91(25.56)$

Breast surgery

$$
\begin{aligned}
& \text { No } \\
& \text { Yes }
\end{aligned}
$$

341 (94.99)

$18(5.01)$

\section{Gastrointestinal disease}

No

Yes

Urinary infection

No

Yes

Vaginal candidiasis

No

Yes

Eye infection

No
Yes

Ear infection

No

Yes

Lip or nose infection

No

Yes

Throat infection

No

Yes
267 (74.17)

93 (25.83)

286 (78.36)

79 (21.64)

$279(76.23)$

87 (23.77)

335 (91.78)

$30(8.22)$

350 (95.89)

$15(4.11)$

285 (77.87)

81 (22.13)

258 (70.88)

106 (29.12)
Control, $n^{*}(\%)$

74 (52.11)

$12(8.45)$

5 (3.52)

51 (35.92)

$121(85.82)$

20 (14.18)

$120(83.92)$

23 (16.08)

54 (87.10)

8 (12.90)

99 (68.28)

46 (31.72)

141 (97.24)

4 (2.76)

$113(76.87)$

34 (23.13)

$128(86.49)$

20 (13.51)

$127(85.81)$

21 (14.19)

139 (93.92)

9 (6.08)

145 (97.97)

$3(2.03)$

$125(84.46)$

23 (15.54)

$126(85.71)$

21 (14.29)
OR

$95 \% \mathrm{Cl}$

$P$-value

Reference

0.369

1.09

1.78

1.41

Reference

0.052

1.69

$0.99-2.90$

Reference

$<0.001$

3.20

$1.93-5.28$

Reference

$<0.001$

7.13

$3.10-16.39$

Reference

0.161

0.74

$0.48-1.13$

Reference

0.378

1.86

$0.62-5.60$

Reference

0.524

1.16

$0.74-1.82$

Reference

0.035

1.77

$1.04-3.01$

Reference

0.016

1.89

$1.12-3.17$

Reference

0.408

1.38

$0.64-2.99$

Reference

0.370

2.07

$0.59-7.26$

Reference

1.54

0.092

$0.93-2.57$

Reference

$<0.001$
$1.47-4.12$ 
Table 1 Medical history of women participating in the study (Continued)

\begin{tabular}{|c|c|c|c|c|c|}
\hline \multicolumn{6}{|c|}{ Skin infection } \\
\hline No & 301 (82.47) & 137 (92.57) & Reference & & \multirow[t]{2}{*}{0.003} \\
\hline Yes & $64(17.53)$ & $11(7.43)$ & 2.65 & $1.35-5.18$ & \\
\hline \multicolumn{6}{|l|}{ Allergies } \\
\hline No & $250(68.31)$ & $106(71.62)$ & Reference & & \multirow[t]{2}{*}{0.461} \\
\hline Yes & $116(31.69)$ & $42(28.38)$ & 1.17 & $0.77-1.78$ & \\
\hline \multicolumn{6}{|c|}{ Autoimmune disease } \\
\hline No & $352(96.17)$ & $146(98.65)$ & Reference & & \multirow[t]{2}{*}{0.237} \\
\hline Yes & $14(3.83)$ & $2(1.35)$ & 2.90 & $0.65-12.94$ & \\
\hline \multicolumn{6}{|l|}{ Asthma } \\
\hline No & 347 (94.81) & $140(94.59)$ & Reference & & \multirow[t]{2}{*}{0.922} \\
\hline Yes & 19 (5.19) & $8(5.41)$ & 0.96 & $0.41-2.24$ & \\
\hline \multicolumn{6}{|l|}{ Anemia } \\
\hline No & 305 (83.33) & $135(91.84)$ & Reference & & \multirow[t]{2}{*}{0.013} \\
\hline Yes & $61(16.67)$ & $12(8.16)$ & 2.25 & $1.17-4.32$ & \\
\hline \multicolumn{6}{|c|}{ Gestational diabetes } \\
\hline No & 342 (93.96) & 139 (93.92) & Reference & & \multirow[t]{2}{*}{0.987} \\
\hline Yes & $22(6.04)$ & $9(6.08)$ & 0.99 & $0.45-2.21$ & \\
\hline \multicolumn{6}{|c|}{ Thyroid disease } \\
\hline No & 335 (91.78) & $133(89.86)$ & Reference & & \multirow[t]{2}{*}{0.487} \\
\hline Yes & $30(8.22)$ & $15(10.14)$ & 0.79 & $0.41-1.52$ & \\
\hline \multicolumn{6}{|l|}{ Smoker } \\
\hline No & $291(80.17)$ & 116 (78.38) & Reference & & \multirow[t]{2}{*}{0.649} \\
\hline Yes & $72(19.83)$ & $32(21.62)$ & 0.90 & $0.56-1.43$ & \\
\hline \multicolumn{6}{|c|}{ Social drinker } \\
\hline No & $195(54.17)$ & $84(57.14)$ & Reference & & \multirow[t]{2}{*}{0.541} \\
\hline Yes & $165(45.83)$ & $63(42.86)$ & 1.13 & $0.77-1.66$ & \\
\hline
\end{tabular}

Cases and controls were asked to present any of these medical conditions from 6 months before pregnancy to delivery.

$O R$, odds ratio; $\mathrm{Cl}$, confidence interval.

*The number of cases varies because of missing data.

**Data from primiparous women were excluded for this analysis.

procedure, adding the predictor with the largest score statistic. Variables which were significant by the Wald statistic at $P<0.05$ were included in the final model. Adjusted OR (AOR) and 95\% CI were calculated for the selected variables in the multivariate logistic regression model. Adequacy of the multivariate model was estimated by Hosmer-Lemeshow test and the area under the Receiver Operating Characteristic (ROC) curve.

The Statgraphics Centurion XVI software (16.1.03) (StatPoint Technologies, Inc., Warrenton, VA, USA) and the SAS software, version 9.2 (SAS Institute, Inc., Cary, NC, USA) were used for these analyses.

\section{Results}

A total of 368 cases (mastitis) and 148 controls (healthy women) were included in the study after filling out a questionnaire designed to collect retrospective information about different factors that could be involved in mastitis.

Concerning demographic characteristics, there were no significant differences between case and control subjects with regard to mean age at last delivery (cases: 33.7 years, 95\% CI: 33.01-34.19; controls: 33.6 years, 95\% CI: 33.32-34.12; $P=0.756$ ), infant weight (cases: $3.33 \mathrm{~kg}, 95 \%$ CI: 3.28-3.35; controls: $3.32 \mathrm{~kg}$, 95\% CI: 3.27-3.38; $P=0.786$ ) and infant size (cases: $49.83 \mathrm{~cm}$, 95\% CI: 49.64-50.02; controls: $50.17 \mathrm{~cm}, 95 \% \mathrm{CI}$ : 49.8750.46; $P=0.186$ ). However, the mean infant age when the mother completed the questionnaire was significantly different $(P<0.001)$ between cases $(3.35$ months; 95\% CI: 2.91-3.79) and controls (6.68 months; 95\% CI: 5.93-7.42).

The bivariate analysis for qualitative variables that could be related to mastitis is shown in Tables $1,2,3$ 
Table 2 Medical history of breastfed infants participating in the study

\begin{tabular}{|c|c|c|c|c|c|}
\hline Variables & Case, $n^{*}(\%)$ & Control, $n^{*}(\%)$ & OR & $95 \% \mathrm{Cl}$ & $P$-value \\
\hline \multicolumn{6}{|l|}{ Sex } \\
\hline Female & $157(42.90)$ & $78(52.70)$ & Reference & & \\
\hline Male & $209(57.10)$ & $70(47.30)$ & 1.48 & $1.01-2.18$ & 0.043 \\
\hline \multicolumn{6}{|l|}{ Blood type } \\
\hline A & 104 (39.69) & $51(48.11)$ & Reference & & \\
\hline B & $29(11.07)$ & $4(3.77)$ & 3.56 & $1.19-10.66$ & 0.011 \\
\hline$A B$ & $16(6.11)$ & $1(0.94)$ & 7.85 & $1.01-60.82$ & \\
\hline O & $113(43.13)$ & $50(47.17)$ & 1.11 & $0.69-1.78$ & \\
\hline \multicolumn{6}{|l|}{ Rh factor } \\
\hline Positive & 240 (91.60) & 100 (94.34) & Reference & & \\
\hline Negative & $22(8.40)$ & $6(5.66)$ & 1.53 & $0.60-3.88$ & 0.370 \\
\hline \multicolumn{6}{|l|}{ APGAR test } \\
\hline$<9$ & $26(7.60)$ & $3(2.26)$ & Reference & & \\
\hline$>9$ & 316 (92.40) & 130 (97.74) & 0.28 & $0.08-0.94$ & 0.049 \\
\hline \multicolumn{6}{|l|}{ Jaundice } \\
\hline No & $244(67.22)$ & 109 (74.15) & Reference & & \\
\hline Yes & 119 (32.78) & $38(25.85)$ & 1.40 & $0.91-2.15$ & 0.125 \\
\hline \multicolumn{6}{|l|}{ Hypoglycemia } \\
\hline No & 357 (97.01) & 143 (96.62) & Reference & & \\
\hline Yes & $11(2.99)$ & $5(3.38)$ & 0.88 & $0.30-2.58$ & 0.818 \\
\hline \multicolumn{6}{|l|}{ Eczema } \\
\hline No & 347 (94.29) & $141(95.27)$ & Reference & & \\
\hline Yes & $21(5.71)$ & $7(4.73)$ & 1.22 & $0.51-2.93$ & 0.658 \\
\hline \multicolumn{6}{|l|}{ Thrush } \\
\hline No & 328 (89.13) & 143 (96.62) & Reference & & \\
\hline Yes & $40(10.87)$ & $5(3.38)$ & 3.49 & $1.35-9.02$ & 0.006 \\
\hline \multicolumn{6}{|c|}{ Micrognathia/Retrognathia } \\
\hline No & 355 (96.47) & 147 (99.32) & Reference & & \\
\hline Yes & $13(3.53)$ & $1(0.68)$ & 5.38 & $0.70-41.52$ & 0.132 \\
\hline \multicolumn{6}{|l|}{ Tongue-tie } \\
\hline No & 255 (71.63) & 134 (90.54) & Reference & & \\
\hline Yes & $101(28.37)$ & $14(9.46)$ & 3.79 & $2.09-6.89$ & $<0.001$ \\
\hline \multicolumn{6}{|c|}{ Child hospitalized after birth } \\
\hline No & $323(90.73)$ & $134(96.40)$ & Reference & & \\
\hline Yes & $33(9.27)$ & $5(3.60)$ & 2.74 & $1.05-7.16$ & 0.033 \\
\hline
\end{tabular}

$O R$, odds ratio; $\mathrm{Cl}$, confidence interval.

*The number of cases varies because of missing data.

and 4, where the results are presented as percentages, ORs and $95 \% \mathrm{CI}$.

The factors related to the medical history of the women participating in this study are shown in Table 1 . Compared with controls, a history of mastitis in the family (OR: 3.20) or in previous lactations (OR: 7.13) were strongly associated with a higher risk of mastitis. There were no significant differences between the case patients and the control subjects with regard to blood type, Rh factor, history of breast cancer in the family, breast surgery or the presence of a gastrointestinal disease.

Women with mastitis were more likely to report urinary infection (OR: 1.77) and vaginal candidiasis (OR: 1.89) than controls, as well as throat (OR: 2.47) and skin infection (OR: 2.65). In addition, significantly more casepatients than controls reported anemia (OR: 2.25). No 
Table 3 Pregnancy, delivery and postpartum characteristics of participants in this study

\section{Variables \\ Threatened miscarriage}

No

Yes

Breast/nipple pain during pregnancy

$$
\text { No }
$$

Yes

Antibiotics during pregnancy

$$
\text { No }
$$$$
\text { Yes }
$$

Antifungal medication during pregnancy

$$
\begin{aligned}
& \text { No } \\
& \text { Yes }
\end{aligned}
$$

\section{Analgesics during pregnancy}

No

Yes

Group B Streptococcus positive test

$$
\text { No }
$$

Yes

Age range at last delivery

$$
\begin{aligned}
& <25 \\
& 25-35 \\
& >35
\end{aligned}
$$

$$
\begin{gathered}
317(89.30) \\
38(10.70)
\end{gathered}
$$

$$
278 \text { (79.89) }
$$

Primiparous/Multiparous

$$
\begin{gathered}
\text { Multiparous } \\
\text { Primiparous } \\
\text { Place of delivery } \\
\text { Private clinic } \\
\text { Public hospital } \\
\text { Home }
\end{gathered}
$$

Type of delivery

$$
\begin{aligned}
& \text { Vaginal } \\
& \text { Caesarean section }
\end{aligned}
$$

Antibiotherapy during delivery

No
Yes

Epidural analgesia during delivery

$$
\text { No }
$$$$
\text { Yes }
$$

233 (64.36)

129 (35.64)$$
70 \text { (20.11) }
$$

$$
5 \text { (1.37) }
$$

242 (66.12)

119 (32.51)

$$
\text { Control, } n^{*} \text { (\%) }
$$

135 (91.22)

13 (8.78)

117 (80.14)

29 (19.86)

122 (82.43)

26 (17.57)

138 (93.24)

10 (6.76)

105 (71.43)

42 (28.57)

115 (80.99)

27 (19.01)

5 (3.45)

95 (65.52)

45 (31.03)

113 (30.87)

62 (42.18)

85 (57.82)

25 (17.01)

113 (76.87)

9 (6.12)

125 (85.03)

$22(14.97)$

100 (67.57)

48 (32.43)

48 (32.43)

100 (67.57)
OR

Reference

1.82

Reference

1.65

Reference

0.252

1.33

$0.81-2.18$

Reference

0.170

1.65

0.80-3.41

Reference

0.126

1.38

$0.91-2.10$

Reference

1.07

$0.65-1.76$

Reference

0.305

2.55

$0.72-9.00$

2.64

0.73-9.57

Reference

0.015

1.63

$1.10-2.43$

Reference

0.021

0.42

$0.26-0.68$

0.19

$0.07-0.54$

Reference

0.042

1.70

$1.01-2.86$

Reference

0.038

1.53

$1.02-2.30$

Reference

0.003

1.90

$1.24-2.92$ 
Table 3 Pregnancy, delivery and postpartum characteristics of participants in this study (Continued)

\begin{tabular}{|c|c|c|c|c|c|}
\hline \multicolumn{6}{|c|}{ First contact with child } \\
\hline Immediately & $243(66.21)$ & $114(77.51)$ & Reference & & \multirow[t]{3}{*}{0.019} \\
\hline $10-60 \min$ & $78(21.25)$ & $25(17.01)$ & 1.46 & $0.89-2.42$ & \\
\hline$>60 \min$ & $46(12.53)$ & $8(5.44)$ & 2.70 & $1.23-5.90$ & \\
\hline \multicolumn{6}{|c|}{ Separation child-mother longer than $24 \mathrm{~h}$} \\
\hline No & $330(89.92)$ & $144(97.30)$ & Reference & & \multirow[t]{2}{*}{0.009} \\
\hline Yes & $37(10.08)$ & $4(2.70)$ & 4.04 & $1.41-11.53$ & \\
\hline
\end{tabular}

$O R$, odds ratio; $\mathrm{Cl}$, confidence interval.

*The number of cases varies because of missing data.

significant differences were found between both groups regarding smoking or drinking habit.

Some factors related to the infant medical history are shown in Table 2. Infant blood type B was significantly more reported by women with mastitis compared to controls (OR: 3.56). No differences were found related to $\mathrm{Rh}$ factor. However, there was a marginally significant difference regarding child gender, so that more casepatients declared to give birth to a male child compared to controls (OR: 1.48). APGAR test score $>9$ was found to be a barely significant protective factor (OR: 0.28 ).

No significant differences were observed in relation to jaundice, hypoglycemia, eczema or micrognathia/retrognathia, but significantly more infants from mothers with mastitis suffered oral thrush (OR: 3.49). The presence of tongue-tie in the infant (OR: 3.79) and infant hospitalization after birth (OR: 2.74) were significantly more reported in the mastitis group.

Characteristics of pregnancy, delivery and postpartum are shown in Table 3 . There was not a statistically significant difference between cases and controls related to a threatened miscarriage. In contrast, a history of breast/ nipple pain during pregnancy was significantly more common among women with mastitis (OR: 1.65).

The use of antibiotics, antifungal treatment and analgesics during pregnancy between cases and controls was not statistically different. However, antibiotherapy (OR: 1.53) and epidural analgesia (OR: 1.90) during delivery were significantly more widely administered to women reporting mastitis. There were no age-related significant differences at delivery, but primiparous women were found significantly more often in the mastitis group (69.13\%) than in the control group (57.82\%).

Place and type of delivery also showed significant differences between cases and controls. Delivery in a public hospital (OR: 0.42) had a significant protective effect compared to delivery in a private clinic, while Caesarean sections were performed on women in the mastitis group at significantly higher frequency $(23.05 \%)$ than on those in the control group (14.97\%).

Contact with the infant immediately after birth was more likely reported by controls (77.51\%) than cases (66.21\%), while the mastitis group reported more often (12.53\%) that the first contact took at least one hour after birth compared to controls (5.44\%). A higher risk of mastitis was noted when the infant was separated from the mother for more than $24 \mathrm{~h}$ (OR: 4.04).

Breastfeeding characteristics and practices are shown in Table 4. Breastfeeding started immediately after birth significantly more often in controls than in cases (83.56\% and $71.58 \%$, respectively). Exclusive breastfeeding (OR: 0.32) and breastfeeding twins/tandem nursing (OR: 0.26) were also more common in the control group. Women having children with latching problems were about 2.7 times more likely to report mastitis (OR: 2.68), and similar results were found if there was a delay of several days in breast milk coming in (OR: 2.77). Perceiving a low milk supply (OR: 3.19) or an oversupply (OR: 1.54) also turned out to be described significantly most often by women suffering from mastitis.

Women with mastitis were more likely to use more breastfeeding positions (39.61\%) than controls (27.78\%) although it may be a consequence of the pain while breastfeeding. In addition, breastfeeding longer than 45 minutes was significantly associated with mastitis (OR: 4.77).

The use of pacifiers, bottle-feeding or nipple shields, that might interfere with proper suckling in some situations, was significantly more frequent among cases (approximately 1.6 times (OR: 1.58), 4.10 times (OR: 4.10) and 4.4 times (OR: 4.36) higher, respectively). The number of controls reporting flat or inverted nipples was insufficient to describe precisely the relationship between this condition and the risk of mastitis. Other breastfeeding practices strongly linked to women with mastitis included the use of creams (OR: 3.39) and pumps (OR: 3.47).

Women were asked to rate cracked nipples on a 5point scale, from 1 (no cracked nipples) to 5 (severely cracked nipples). Cracked nipples rated 3 to 5 were more frequently reported by women with mastitis compared to controls, especially severely cracked ones (OR: 7.03).

Use of oral antibiotic (OR: 4.58) and topical antifungal (OR: 2.67) drugs was significantly associated with mastitis. Use of analgesics (OR: 1.94) and non-steroidal anti- 
Table 4 Breastfeeding characteristics and practices of the women involved in this study

\section{Variables \\ First breastfeed after birth}

$$
\begin{aligned}
& \text { Not immediately } \\
& \text { Immediately }
\end{aligned}
$$

Problems to latch on the nipple at first

$$
\begin{aligned}
& \text { No } \\
& \text { Yes }
\end{aligned}
$$

Time until the milk come in

$$
\text { Hours }
$$

Several days

Breast milk amount

$$
\begin{aligned}
& \text { Normal } \\
& \text { Oversupply } \\
& \text { Low supply }
\end{aligned}
$$

Types of breastfeeding

$$
\begin{aligned}
& \text { Mixed } \\
& \text { Exclusive }
\end{aligned}
$$

Breastfeeding twins/Tandem nursing

$$
\begin{aligned}
& \text { No } \\
& \text { Yes }
\end{aligned}
$$

\section{Breastfeeding positions}

1

2

3

Breastfeeding length

$$
\begin{aligned}
& \text { 5-15 min } \\
& \text { 15-30 min } \\
& \text { 30-45 min } \\
& >45 \mathrm{~min}
\end{aligned}
$$

Time since breastfeeding started

$$
\begin{aligned}
& <2 \text { weeks } \\
& \text { 2-4 weeks } \\
& \text { 1-3 months } \\
& \text { 3-6 months } \\
& \text { 6-12 months } \\
& >12 \text { months }
\end{aligned}
$$

\section{Breast preference}

No
Yes

Consecutive feeds start with same breast

$$
\text { No }
$$$$
\text { Yes }
$$

$$
\text { Case, } n^{*}(\%)
$$

$104(28.42)$

262 (71.58)

24 (16.44)

122 (83.56)

250 (67.93)

125 (85.03)

22 (14.97)

50 (13.77)

42 (29.17)

66 (18.18)

247 (68.04)

185 (50.27)

139 (37.77)

44 (11.96)

272 (75.35)

89 (24.65)

349 (96.41)

13 (3.59)

48 (13.30)

170 (47.09)

143 (39.61)

71 (26.59)

112 (41.95)

37 (13.86)

47 (17.60)

31 (8.59)

61 (16.90)

161 (44.60)

52 (14.40)

$30(8.31)$

$26(7.20)$

233 (64.19)

130 (35.81)

331 (92.72)

$26(7.28)$
27 (18.75)

75 (52.08)

94 (63.95)

48 (31.29)

7 (4.76)

14 (9.52)

133 (90.48)

126 (87.50)

18 (12.50)

22 (15.28)

82 (56.94)

40 (27.78)

36 (41.38)

38 (43.68)

$8(9.20)$

5 (5.75)

3 (2.59)

8 (6.90)

22 (18.97)

51 (43.97)

15 (12.93)

$17(14.66)$

104 (71.23)

42 (28.77)

137 (93.84)

9 (6.16)

OR

Reference

0.50

95\% C

$P$-value

0.005

$0.30-0.81$

Reference

$<0.001$

2.68

$1.62-4.44$

Reference

$<0.001$

$$
2.05
$$

1.12-3.77

2.77

$1.70-4.49$

Reference

0.006

1.54

$1.01-2.33$

3.19

$1.39-7.36$

Reference

$<0.001$

0.32

$0.18-0.59$

Reference

$<0.001$

0.26

$0.12-0.55$

1.05

$0.60-1.86$

0.043

Reference

1.72

$1.11-2.67$

Reference

$<0.001$

1.49

$0.87-2.58$

2.35

0.99-5.56

4.77

1.74-13.03

Reference

$<0.001$

$\begin{array}{ll}0.74 & 0.18-2.98 \\ 0.71 & 0.20-2.51 \\ 0.10 & 0.03-0.34 \\ 0.19 & 0.05-0.74 \\ 0.15 & 0.04-0.56\end{array}$

Reference

0.129

1.38

$0.91-2.10$

Reference

0.655 
Table 4 Breastfeeding characteristics and practices of the women involved in this study (Continued)

One or two breast in each session

1
2

Child skips one breastfeed session

No

Yes

Pacifier

No

Yes

Nipple shields

No

Yes

Bottle-feeding

No

Yes

Flat or inverted nipples
No
Yes

Cream on nipples

No

Yes

Breast pumps

No

Yes

Breast pads

No

Yes

Brassier use

$$
\begin{aligned}
& \text { Day and night } \\
& \text { Only day }
\end{aligned}
$$

Cracked nipples (1-5)

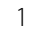

2

3

4

5

Antibiotics during breastfeeding

$$
\text { No }
$$$$
\text { Yes }
$$

Antifungal medication during breastfeeding

$$
\text { No }
$$$$
\text { Yes }
$$

Analgesics during breastfeeding

No

Yes
$138(43.13)$

$182(56.88)$

274 (96.14)

$11(3.86)$

235 (66.38)

119 (33.62)

291 (82.20)

$63(17.80)$

260 (73.45)

$94(26.55)$

$323(91.24)$

$31(8.76)$

$171(47.63)$

$188(52.37)$

$143(39.29)$

$221(60.71)$

116 (32.77)

238 (67.23)

170 (48.99)

177 (51.01)

73 (19.84)

42 (11.41)

50 (13.59)

43 (11.68)

160 (43.48)

207 (56.71)

158 (43.29)

280 (76.71)

85 (23.29)

217 (58.97)

151 (41.03)
54 (40.30)

80 (59.70)

117 (99.15)

$1(0.85)$

112 (75.68)

36 (24.32)

141 (95.27)

7 (4.73)

136 (91.89)

12 (8.11)

147 (99.32)

1 (0.68)

108 (75.52)

35 (24.48)

101 (69.18)

45 (30.82)

56 (38.89)

88 (61.11)

72 (54.96)

$59(45.04)$

77 (52.03)

26 (17.57)

12 (8.11)

9 (6.08)

24 (16.22)

126 (85.71)

21 (14.29)

132 (89.80)

15 (10.20)

109 (73.65)

39 (26.35)
Reference

0.89

Reference

4.70

Reference

1.58

Reference

4.36

Reference

4.10

Reference

14.11

Reference

3.39

Reference

3.47

Reference

1.31

Reference

1.27

Reference

1.70

4.39

5.04

7.03

Reference

4.58

Reference

2.67

Reference

1.94

$1.28-2.96$
0.578

$0.59-1.34$

0.195

$0.60-36.80$

$1.02-2.44$

1.95-9.77

$<0.001$

$2.17-7.74$

0.002

1.91-104.34

$2.20-5.24$

$<0.001$

$2.30-5.22$

0.87-1.95

0.193

0.244

0.85-1.90

0.95-3.06

2.17-8.91

2.30-11.07

4.02-12.01

$2.76-7.60$

$<0.001$

$<0.001$

$1,49-4,80$

$$
<0.001
$$


Table 4 Breastfeeding characteristics and practices of the women involved in this study (Continued)

\begin{tabular}{lcccr}
\hline Non-steroidal anti-inflammatory drugs & & & & \\
No & $218(59.24)$ & $119(80.41)$ & Reference & \\
Yes & $150(40.76)$ & $29(19.59)$ & 2.82 & $1.79-4.45$ \\
Corticosteroids & & & & 0.001 \\
No & $355(96.47)$ & $146(98.65)$ & Reference & 0.297 \\
Yes & $13(3.53)$ & $2(1.35)$ & 2.67 & $0.60-11.99$ \\
\hline
\end{tabular}

$O R$, odds ratio; $\mathrm{Cl}$, confidence interval.

*The number of cases varies because of missing data.

${ }^{* *}$ Cracked nipples were rated from 1 (no cracked) to 5 (severely cracked).

inflammatory drugs (OR: 2.82) also showed significant differences between cases and controls. Oral corticosteroid therapies did not yield a significant difference since their use was very low among the analyzed sample.

All statistical significant variables related to mother medical history (Table 1) and pregnancy, delivery and postpartum characteristics (Table 3) were included in the multivariable logistic regression model. However, 8 variables with a $P$ value $<0.05$ were excluded from the multivariable analysis for several reasons. Regarding infant medical history (Table 2) the following were not included: sex and APGAR test (marginally significant difference), blood type (small sample size in controls), tongue tie (condition underrated in the control group) and child hospitalized after birth, because all of them were separated from their mother longer than $24 \mathrm{~h}$ and this factor was included in the multivariable analysis. Concerning breastfeeding characteristics and practices (Table 4) the variables not included were: breastfeeding positions (clearly linked to pain in women with mastitis), flat or inverted nipples (small sample size in controls) and breastfeeding length.
AOR, 95\% CI, and $P$ values of the multivariate logisticregression model determined by forward stepwise selection are shown in Table 5. After adjustment for potentially correlated covariates, the factors significantly- and independentlyassociated with mastitis were history of mastitis in the family (AOR: 2.28), mastitis in previous lactations (AOR: 3.91) and throat infection (AOR: 2.05), in relation to the history of the mother. A mother-infant separation longer than $24 \mathrm{~h}$ after birth increased the risk of suffering mastitis about 6 times (AOR: 6.40). Regarding breastfeeding, the variables most significantly- and independently-associated with mastitis were infant age (AOR: 0.92), breast milk coming in later than 24 h postpartum (AOR: 2.26), cracked nipples (AOR: 1.43) and use of creams (AOR: 1.91), breast pumps (AOR: 2.78), oral antibiotics (AOR: 5.38) and topical antifungal medication (AOR: 3.81).

The Hosmer-Lemeshow goodness-of-fit test showed a Chi-square of $7.32(P=0.503)$ and the area under the ROC curve was 0.870 (95\% CI $=0.835-0.904)$, which means that the model presented a good fit and a good adjustment.

Table 5 Risk factors for mastitis according to multiple logistic regression analysis

\begin{tabular}{lccc}
\hline Variables & Adjusted OR & 95\% Cl & $P$-value \\
\hline Cracked nipples & 1.43 & $1.23-1.67$ & $<0.0001$ \\
Antibiotics during breastfeeding & 5.38 & $2.85-10.14$ & $<.0001$ \\
Infant age & 0.92 & $0.87-0.96$ & $<.0001$ \\
Breast pumps & 2.78 & $1.68-4.58$ & 0.0001 \\
Antifungal medication during breastfeeding & 3.81 & $1.35-10.76$ & 0.0009 \\
Mastitis in previous breastfeeding & 3.91 & $1.60-9.56$ & 0.0014 \\
Breast milk coming in later than 24 $\mathrm{n}$ & 2.26 & $1.24-4.12$ & 0.0016 \\
Mastitis in the family & 2.28 & $1.26-4.13$ & 0.0028 \\
Separation child-mother longer than 24 h & 6.40 & $1.77-23.18$ & 0.0027 \\
Cream on nipples & 1.91 & $1.13-3.24$ & 0.0228 \\
Throat infection & 2.05 & $1.10-3.80$ & 0.0224 \\
\hline
\end{tabular}

$O R$, odds ratio; $\mathrm{Cl}$, confidence interval.

The following variables have been included in the analysis: infant age; mastitis in the family and in previous breastfeeding; urinary, throat and skin infection; vaginal candidiasis; anemia; thrush; breast/nipple pain during pregnancy; parity; place and type of delivery; antibiotherapy and analgesia during delivery; first contact with child; separation child-mother longer than 24 h; first breastfeed after birth; problems to latch on nipple at first; time until the milk comes in; milk amount; mixed/exclusive breastfeeding; breastfeeding two children; time since breastfeeding started; pacifier; nipple shields; bottle-feeding; cream on nipples; breast pumps; cracked nipples; antibiotics, antifungal medication, analgesics and non-steroidal anti-inflammatory drugs during breastfeeding. 


\section{Discussion}

The purpose of this case-control investigation was to identify factors associated with mastitis, including potential risk or protective factors. Among them, the separation of the infant from his mother longer than $24 \mathrm{~h}$ after birth due to hospitalization or for any other reason increased the risk of mastitis. This highlights the crucial importance of the first postnatal hours for establishing mother-infant interaction. Among other aspects of pregnancy, delivery and postpartum, Caesarean delivery and antibiotherapy during delivery as well as the use of epidural analgesia in labor were more frequently reported by mothers with mastitis, although these factors were not included in the final model obtained after the multivariable analysis. In this sense, a negative association between Caesarean delivery and breastfeeding exists because postoperative care routines delay the onset of lactation, disrupt motherinfant interaction and inhibit infant suckling [20]. Peripartum antibiotherapy has emerged as a strong risk factor for human mastitis because it induces the selection for antibiotic-resistant bacteria in the mammary gland and the elimination of potential competitors [21,22]. Antibiotics also affect vaginal and intestinal microbiota of the mother [22] and the development of intestinal microbiota in the infant [23]. The link between epidural intrapartum analgesia and breastfeeding difficulties has also been debated [24-26], but there are not conclusive evidences and further studies are required.

Another relevant factor associated with mastitis was the use of antibiotics during breastfeeding. In fact, widespread use of broad spectrum antibiotics is leading to increasing rates of antimicrobial resistance among mastitis-causing agents [27-29]. On the other hand, biofilm formation is an important virulence factor of the strains implicated in mastitis, taking in account that the penetration capacity through bacterial biofilms depends on each antibiotic [30]. Resistance to antibiotics and ability to form biofilms are common findings among mastitis-causing strains and may explain the often recurrent nature of this infectious condition [21]. This fact emphasizes the need of a milk culture and antibiogram for a rational treatment of mastitis $[19,31]$. Widespread antibiotic therapy used to treat throat infections could also affect the mammary gland microbiota and lead to mastitis. Conversely, broad range antibiotics to treat mastitis are linked to a variety of adverse effects, including urinary infections and vaginal candidiasis [32]. Microbial habitats in the human body, including the skin, constitute a network of interrelated communities [33]. This could explain why pathogens involved in throat and urinary infections may spread to the mammary gland and those implicated in mastitis development may spread to throat and urinary tract. In this work, the bivariate analysis revealed that urinary and skin infections were also more frequent among breastfeeding mothers with mastitis. Interestingly, anemia was also more common in the group of women with mastitis, since women suffering from anemia might be more vulnerable to infections. In addition, iron supplements enhance growth and virulence of Staphylococcus aureus and other mastitis-associated species [34]; as a consequence, women receiving them may also be more prone to mastitis. No clinical trials have evaluated the impact of iron supplementation on mastitis but the study of iron acquisition pathways seems to be a good target to define the underlying mechanisms of mastitis severity [35].

Significantly, a history of mastitis with a previous infant also seems to be a strong mastitis predictor $[1,14]$ and, in our study, this factor was associated with an almost four-fold risk of mastitis in the multivariate analysis. Breast health depends on a balanced interaction between the host and its microbiota [36,37]. Since the milk bacterial profile is host-specific [36,38,39], there could be a mammary microbiota more prone to mastitis development [6]. In fact, S. epidermidis, an underrated cause of mastitis, lives at the edge between commensalism and pathogenicity and requires a predisposed host to transform itself into a notorious pathogen $[40,41]$. On the other hand, several oligosaccharides involved in the mucosal immune system are present in human milk [42]. Therefore, differences in profile and concentration of such compounds may explain a differential host susceptibility to develop mastitis [43].

Our results indicate that a familial occurrence of mastitis is a significant risk factor for the disease, which suggests the role of a genetic predisposition in the development of mastitis. The existence of a genetic basis for host responses to bacteria involved in mastitis has been widely documented in cattle and sheep mastitis [44,45], although the underlying mechanisms are still largely unknown. The first association between human granulomatous mastitis caused by Corynebacterium kroppenstedtii and a single nucleotide polymorphism (SNP) related to defective neutrophil responses has been recently described [46], which opens new fields for further investigation in human mastitis.

In our work, antifungal medication during breastfeeding was strongly linked to mastitis. Antifungal ointments are often prescribed to treat "mammary candidiasis" on the basis of visual assessment, without a microbiological analysis. Actually, yeasts are an extremely rare cause of lactational mastitis in any mammalian species and there is lack of evidence to reach such a diagnosis [47-49]. It is interesting to note, however, that there is an association between staphylococcal/streptococcal mastitis and candidiasis (oral thrush) in the infant since a high concentration of such bacteria can induce Candida albicans overgrowth. C. albicans and streptococci form a synergistic partnership where Streptococcus promotes fungal growth by secreting 
metabolic products that can be used as a carbon source by the yeast [50,51]. After C. albicans overgrowth in the infant mouth, some of the yeast cells can be transferred to the mother through breastfeeding, so that $C$. albicans could be isolated from breast milk and misdiagnosed as the cause of mastitis.

On the other hand, nipple cracks have been significantly associated with mastitis in previous studies $[1,7,13-15]$ under the hypothesis that it provides a portal of entry for microorganisms. However, recent studies suggested that nipple lesions can be a precocious clinical sign of mastitis rather than a predisposing factor [21]. Exfoliative or "epidermolytic" toxins are relevant virulence factors of S. aureus and other Staphylococcus species [52]. In fact, an increased milk concentration of staphylococci or streptococci had increased odds for damaged nipples [53]. Our results also revealed that the use of ointments was associated with increased incidence of mastitis, in agreement with previous studies $[1,14]$. Such practice may provide good environmental conditions for bacterial overgrowth and dissemination.

The use of breast pumps was associated with mastitis, although this fact may be a consequence rather than a cause, since pumping is frequently recommended to reduce breast pressure and diminish bacterial load inside the mammary ducts during mastitis [14]. Too much expression may also result in pain from breast overstretching while improper use of an electric pump can lead to mastitis, trauma, and nipple wounds $[1,54]$.

Regarding breastfeeding characteristics and practices, the risk of developing lactational mastitis was also associated with the breast milk coming in later than $24 \mathrm{~h}$ postpartum. Previous studies focused on a potential relationship between positioning, attachment problems and mastitis have provided contradictory results $[13,55]$. The bivariate analysis showed that mastitis was less common in women that breastfed her infant immediately after birth and also in women whose infants did not have difficulties in the first latch. In fact, it has been reported that timing of the first feeding is a key determinant for establishing mother-infant interaction and breastfeeding success [56]. Other factors more frequently found in control women were feeding two children and exclusive breastfeeding versus mixed feeding while the opposite was detected for bottle-feeding, in agreement with other studies [1]. Exclusive breastfeeding not only avoids the use of nursing bottles, but provides better interaction between mother and infant; therefore, increasing the nursing frequency and contributing to an adequate milk drainage. Considering these facts, breastfeeding twins or tandem nursing might be also considered a protective factor for mastitis. Regarding the amount of milk produced, milk over- or undersupply versus normal supply was more likely reported by cases. It has been suggested that mastitis may arise from a higher milk supply because of the risk of milk stasis if the infant delays or misses feeds [13]; this situation may provide good conditions for bacterial overgrowth. On the other hand, low milk supply could give to the mother a false perception of low milk production when, actually, only secretion is compromised due to the formation of thick bacterial biofilms inside the milk ducts $[6,22,57]$. This situation may also lead to longer feedings that were reported by women with mastitis.

Traditionally, interferences with suckling (pacifiers, bottle-feeding or nipple shields) have been related to breastfeeding problems and their use should be avoided, at least while the infant is learning to suckle properly. In our study, those practices were reported more frequently by women with mastitis when the initial bivariate analysis of possible risk factors was performed. In this analysis, a higher prevalence of tongue-tie (ankyloglossia) was found among infants from women with mastitis. However, this condition is not usually considered in infants without breastfeeding difficulties and, consequently, it could be underrated in the control group. The relationship between ankyloglossia and breastfeeding problems has been largely debated. Controversies in this area have arisen from attempts to find an absolute relationship between tongue-tie and breastfeeding difficulties instead of a relative one, where the first increases the risk for the latter [58]. Also, the existence of various classification systems for the diagnosis of ankyloglossia is confusing for clinicians.

Finally, mastitis was apparently associated with the lactation period, and the risk of mastitis decreased with the infant age $(\mathrm{OR}=0.92)$. This could be a confounding factor because there was an age difference between cases (mean 3.35 months) and controls (mean 6.68 months) in spite of the fact that the same midwives and lactation consultants attending various health centers were in charge of recruiting cases (mastitis) and controls (healthy) women over a 21-month period. Actually, this difference in infant age due to unrestricted sampling of subjects may reflect the circumstance that lactational mastitis develops more frequently in the early stages of lactation. A higher incidence of mastitis during the first 4 weeks of breastfeeding and 75-95\% of cases observed in the first 3 months has been reported previously [6]. A reduced number of the variables considered in the study could be influenced by infant's age, including jaundice, hypoglycemia or eczema symptoms; however, the frequency of these conditions did not differ between cases and controls in the initial bivariate analysis. Regarding the length of feedings, feedings longer than $45 \mathrm{~min}$ were more frequently reported by cases. This fact could be related with younger children in cases compared to controls since the younger is the child, the longer is the feeding, but it might also be 
linked to a subclinical mastitis characterized by a decreased milk secretion that induces the baby to have longer feedings. However, taking these facts into account, this variable (feeding longer than $45 \mathrm{~min}$ ) was excluded from the multivariable analysis and further studies will be carried out to clarify the link between breastfeeding length and mastitis.

We must acknowledge that there are other limitations in this study. Firstly, women had a strong commitment to breastfeeding since many of them were members of breastfeeding support groups. Secondly, the data were obtained retrospectively, which leads to a reporting bias due to lack of information about some questions. And thirdly, the results must be carefully interpreted because some identified associations could be consequences of mastitis rather than its causes, which is also a limitation in the design of case-control studies. On the other hand, further studies are needed to confirm the relationship between mastitis and all the exploratory variables of this study that have not been considered in previous research findings. Additionally, the long and complex questionnaire, as well as the elapsed time from the analyses of milk samples to the questionnaire reception, accounted for the low response rate in cases (34\%). In fact, this rate would have been improved if the questionnaire had been delivered and responded to by the time the breast milk samples were collected to be analyzed. This fact will be taken into account in future studies to increase the response rates.

\section{Conclusions}

Relevant factors related to an increased risk of infectious mastitis have been identified in this study. This knowledge will allow practitioners to provide appropriate management advice about modifiable risk factors, such as the use of pumps or inappropriate medication. They also could identify those women at an increased risk of developing mastitis, such as those having a familial history of mastitis, before delivery, and thus develop strategies to prevent this condition. There are still many questions to answer about infectious mastitis, but work is in progress to broaden our knowledge in this relevant Public Health issue.

\section{Competing interests}

The authors declare that they have no competing interests.

\section{Authors' contributions}

PM assisted with the study design and data collection. LM contributed to analysis and interpretation of data. JMR originated and directed the study. LF and JMR reviewed the manuscript. MM conducted the study design, analyses and interpretation of the data and wrote the article. All authors read and approved the final manuscript.

\section{Acknowledgments}

We thank all the women, midwives, lactation consultants and medical practitioners who kindly participated in this study and Ricardo García (Universidad Complutense de Madrid) for his assistance in statistical analysis of data. This work was supported by CSD2007-00063 (FUN-C-FOOD, Consolider-Ingenio 2010) and AGL2010-15420 projects from the Ministerio de Ciencia e Innovación (Spain).
Received: 8 July 2013 Accepted: 29 May 2014

Published: 6 June 2014

\section{References}

1. Foxman B, D'Arcy H, Gillespie B, Bobo JK, Schwartz K: Lactation mastitis: occurrence and medical management among 946 breastfeeding women in the United States. Am J Epidemiol 2002, 155:103-114.

2. Betzold CM: An update on the recognition and management of lactational breast inflammation. J Midwifeny Womens Health 2007, 52:595-605.

3. Scott JA, Robertson M, Fitzpatrick J, Knight C, Mulholland S: Occurrence of lactational mastitis and medical management: a prospective cohort study in Glasgow. Int Breastfeed J 2008, 3:21.

4. Spencer JP: Management of mastitis in breastfeeding women. Am Fam Physician 2008, 78:727-731.

5. Kvist L: Re-examination of old truths: replication of a study to measure the incidence of lactational mastitis in breastfeeding women. Int Breastfeed J 2013, 8:2

6. Contreras GA, Rodríguez JM: Mastitis: comparative etiology and epidemiology. J Mammary Gland Biol Neoplasia 2011, 16:339-356.

7. Amir LH, Garland SM, Lumley J: A case-control study of mastitis: nasal carriage of Staphylococcus aureus. BMC Fam Pr 2006, 7:57.

8. Amir LH, Ingram J: Health professionals' advice for breastfeeding problems: not good enough! Int Breastfeed J 2008, 3:22.

9. Ip S, Chung M, Raman G, Trikalinos TA, Lau J: A summary of the Agency for Healthcare Research and Quality's evidence report on breastfeeding in developed countries. Breastfeed Med 2009, 4(Suppl 1):S17-S30.

10. Dieterich CM, Felice JP, O'Sullivan E, Rasmussen KM: Breastfeeding and health outcomes for the mother-infant dyad. Pediatr Clin North Am 2013, 60:31-48.

11. Geddes DT, Prescott SL: Developmental origins of health and disease the role of human milk in preventing disease in the 21st Century. J Hum Lact 2013, 29:123-127.

12. World Health Organization (WHO): Mastitis: Causes and Managemen. Geneva, Switzerland: Dept. of child and adolescent health and development; 2000.

13. Vogel A, Hutchison BL, Mitchell EA: Mastitis in the first year postpartum. Birth 1999, 26:218-225.

14. Kinlay JR, O'Connell DL, Kinlay S: Risk factors for mastitis in breastfeeding women: results of a prospective cohort study. Aust N Z J Public Health 2001, 25:115-120.

15. Amir LH, Forster DA, Lumley J, McLachlan H: A descriptive study of mastitis in Australian breastfeeding women: incidence and determinants. BMC Public Health 2007, 7:62.

16. Spanish National Institute of Statistics: National Health Survey; 2011. http:// www.ine.es/jaxi/tabla.do?type=pcaxis\&path=/t00/mujeres_hombres/ tablas 1/10/8file=d06003.px. [Interactive website; Accessed 17 June 2014].

17. Save the Children: State of the World's Mothers. London, UK; 2012. http///mww. savethechildren.org/atf/cf/\%7B9def2ebe-10ae-432c-9bdo-df91d2eba74a\%7D/STATEOF-THE-WORLDS-MOTHERS-REPORT-2012-FINAL.PDF. [Accessed 17 June 2014].

18. Lactation Committee of the Spanish Association of Paediatrics: Recommendations on Breastfeeding. Spain; 2012. http://www.aeped.es/sites/ default/files/recomendaciones_english.pdf. [Accessed 17 June 2014].

19. Arroyo R, Mediano P, Martín V, Jiménez E, Delgado S, Fernández L, Marín M, Rodríguez JM: Etiological diagnosis of infectious mastitis: proposal of a protocol for the culture of human milk samples. Acta Pediatr Esp 2011, 69:276-281.

20. Prior E, Santhakumaran S, Gale C, Philipps LH, Modi N, Hyde MJ: Breastfeeding after cesarean delivery: a systematic review and meta-analysis of world literature. Am J Clin Nutr 2012, 95:1113-1135.

21. Arroyo R, Martín V, Maldonado A, Jiménez E, Fernández L, Rodríguez JM: Treatment of infectious mastitis during lactation: antibiotics versus oral administration of Lactobacilli isolated from breast milk. Clin Infect Dis 2010, 50:1551-1558.

22. Delgado S, Arroyo R, Jiménez E, Marín ML, del Campo R, Fernández L, Rodríguez JM: Staphylococcus epidermidis strains isolated from breast milk of women suffering infectious mastitis: potential virulence traits and resistance to antibiotics. BMC Microbiol 2009, 9:82.

23. Tanaka S, Kobayashi T, Songjinda P, Tateyama A, Tsubouchi M, Kiyohara C, Shirakawa T, Sonomoto K, Nakayama J: Influence of antibiotic exposure in the early postnatal period on the development of intestinal microbiota. FEMS Immunol Med Microbiol 2009, 56:80-87. 
24. Camann W: Labor analgesia and breast feeding: avoid parenteral narcotics and provide lactation support. Int J Obstet Anesth 2007, 16:199-201.

25. Handlin $L$, Jonas W, Petersson $M$, Ejdebäck $M$, Ransjö-Arvidson A-B, Nissen $E$, Uvnäs-Moberg K: Effects of sucking and skin-to-skin contact on maternal ACTH and cortisol levels during the second day postpartum-influence of epidural analgesia and oxytocin in the perinatal period. Breastfeed Med 2009, 4:207-220

26. Loubert C, Hinova A, Fernando R: Update on modern neuraxial analgesia in labour: a review of the literature of the last 5 years. Anaesthesia 2011, 66:191-212

27. Reddy P, Qi C, Zembower T, Noskin GA, Bolon M: Postpartum mastitis and community-acquired methicillin-resistant Staphylococcus aureus. Emerg Infect Dis 2007, 13:298-301.

28. Jahanfar S, $\mathrm{Ng} \mathrm{CJ}$, Teng CL: Antibiotics for mastitis in breastfeeding women. Cochrane Database Syst Rev 2013, 2, CD005458.

29. Barlow J: Mastitis therapy and antimicrobial susceptibility: a multispecies review with a focus on antibiotic treatment of mastitis in dairy cattle. J Mammary Gland Biol Neoplasia 2011, 16:383-407.

30. Høiby N, Bjarnsholt T, Givskov M, Molin S, Ciofu O: Antibiotic resistance of bacterial biofilms. Int J Antimicrob Agents 2010, 35:322-332

31. Carrera M, Arroyo R, Mediano P, Fernández L, Marín M, Rodríguez JM: Breastfeeding and mastitis. Empirical treatment based on symptoms and etiological agents. Acta Pediatr Esp 2012, 70:255-261.

32. Pirotta MV, Garland SM: Genital Candida species detected in samples from women in Melbourne, Australia, before and after treatment with antibiotics. J Clin Microbiol 2006, 44:3213-3217.

33. Costello EK, Lauber CL, Hamady M, Fierer N, Gordon Jl, Knight R: Bacterial community variation in human body habitats across space and time. Science 2009, 326:1694-1697.

34. Lowy FD: How Staphylococcus aureus adapts to its host. N Engl J Med 2011, 364:1987-1990.

35. Le Maréchal C, Seyffert N, Jardin J, Hernandez D, Jan G, Rault L, Azevedo V, François P, Schrenzel J, van de Guchte M, Even S, Berkova N, Thiéry R, Fitzgerald JR, Vautor E, Le Loir Y: Molecular basis of virulence in Staphylococcus aureus mastitis. PLoS One 2011, 6:e27354.

36. Hunt KM, Foster JA, Forney LJ, Schütte UME, Beck DL, Abdo Z, Fox LK, Williams JE, McGuire MK, McGuire MA: Characterization of the diversity and temporal stability of bacterial communities in human milk. PLoS One 2011, 6:e21313.

37. Fernández L, Langa S, Martín V, Maldonado A, Jiménez E, Martín R, Rodríguez JM: The human milk microbiota: origin and potential roles in health and disease. Pharmacol Res 2013, 69:1-10.

38. Martín R, Heilig HGHJ, Zoetendal EG, Jiménez E, Fernández L, Smidt H, Rodríguez JM: Cultivation-independent assessment of the bacterial diversity of breast milk among healthy women. Res Microbio/ 2007, 158:31-37.

39. Cabrera-Rubio R, Collado MC, Laitinen K, Salminen S, Isolauri E, Mira A: The human milk microbiome changes over lactation and is shaped by maternal weight and mode of delivery. Am J Clin Nutr 2012, 96:544-551.

40. Otto M: Staphylococcus epidermidis-the "accidental" pathogen. Nat Rev Microbiol 2009, 7:555-567.

41. Schoenfelder SMK, Lange C, Eckart M, Hennig S, Kozytska S, Ziebuhr W: Success through diversity - how Staphylococcus epidermidis establishes as a nosocomial pathogen. Int J Med Microbiol 2010, 300:380-386.

42. Hettinga $K$, van Valenberg $H$, de Vries $S$, Boeren $S$, van Hooijdonk $T$, van Arendonk J, Vervoort J: The host defense proteome of human and bovine milk. PLoS One 2011, 6:e19433.

43. Chichlowski M, German JB, Lebrilla CB, Mills DA: The influence of milk oligosaccharides on microbiota of infants: opportunities for formulas. Annu Rev Food Sci Technol 2011, 2:331-351.

44. Hameed KGA, Sender G, Mayntz M: Major histocompatibility complex polymorphism and mastitis resistance-a review. Anim Sci Pap Reports 2006, 24:11-25.

45. Bonnefont CMD, Toufeer M, Caubet C, Foulon E, Tasca C, Aurel M-R, Bergonier D, Boullier S, Robert-Granié C, Foucras G, Rupp R: Transcriptomic analysis of milk somatic cells in mastitis resistant and susceptible sheep upon challenge with Staphylococcus epidermidis and Staphylococcus aureus. BMC Genomics 2011, 12:208.

46. Bercot B, Kannengiesser C, Oudin C, Grandchamp B, Sanson-le Pors M-J, Mouly S, Elbim C: First description of NOD2 variant associated with defective neutrophil responses in a woman with granulomatous mastitis related to corynebacteria. J Clin Microbiol 2009, 47:3034-3037.

47. Francis-Morrill J, Heinig MJ, Pappagianis D, Dewey KG: Diagnostic value of signs and symptoms of mammary candidosis among lactating women. J Hum Lact 2004, 20:288-295. quiz 296-299.

48. Hale TW, Bateman TL, Finkelman MA, Berens PD: The absence of Candida albicans in milk samples of women with clinical symptoms of ductal candidiasis. Breastfeed Med 2009, 4:57-61.

49. Scaccabarozzi L, Locatelli C, Pisoni G, Manarolla G, Casula A, Bronzo V, Moroni P: Short communication: epidemiology and genotyping of Candida rugosa strains responsible for persistent intramammary infections in dairy cows. J Dairy Sci 2011, 94:4574-4577.

50. Shirtliff ME, Peters BM, Jabra-Rizk MA: Cross-kingdom interactions: Candida albicans and bacteria. FEMS Microbiol Lett 2009, 299:1-8.

51. Beaussart A, Herman P, El-Kirat-Chatel S, Lipke PN, Kucharíková S, Van Dijck $P$, Dufrêne YF: Single-cell force spectroscopy of the medically important Staphylococcus epidermidis-Candida albicans interaction. Nanoscale 2013, 5:10894-10900.

52. Bukowski M, Wladyka B, Dubin G: Exfoliative toxins of Staphylococcus aureus. Toxins (Basel) 2010, 2:1148-1165

53. Kvist L, Larsson BW, Hall-Lord ML, Steen A, Schalén C: The role of bacteria in lactational mastitis and some considerations of the use of antibiotic treatment. Int Breastfeed J 2008, 3:6.

54. Rasmussen KM, Geraghty SR: The quiet revolution: breastfeeding transformed with the use of breast pumps. Am J Public Health 2011, 101:1356-1359.

55. Goyal RC, Banginwar AS, Ziyo F, Toweir AA: Breastfeeding practices: Positioning, attachment (latch-on) and effective suckling - A hospital-based study in Libya. J Fam Community Med 2011, 18:74-79.

56. Chien L-Y, Tai C-J: Effect of delivery method and timing of breastfeeding initiation on breastfeeding outcomes in Taiwan. Birth 2007, 34:123-130.

57. Jiménez E, Delgado S, Arroyo R, Fernández L, Rodríguez JM: Infectious mastitis during lactation: an underrated condition (II). Acta Pediatr Esp 2009, 67:125-132.

58. Kumar M, Kalke E: Tongue-tie, breastfeeding difficulties and the role of Frenotomy. Acta Paediatr 2012, 101:687-689.

doi:10.1186/1471-2393-14-195

Cite this article as: Mediano et al:: Case-control study of risk factors for infectious mastitis in Spanish breastfeeding women. BMC Pregnancy and Childbirth 2014 14:195.

\section{Submit your next manuscript to BioMed Central and take full advantage of:}

- Convenient online submission

- Thorough peer review

- No space constraints or color figure charges

- Immediate publication on acceptance

- Inclusion in PubMed, CAS, Scopus and Google Scholar

- Research which is freely available for redistribution

Submit your manuscript at www.biomedcentral.com/submit 